\title{
Levente Seláf, Patricia Noel Aziz Hanna y Joost van DrIEL: Formes strophiques simples/Simple Strophic Patterns. Budapest: Akadémiai Kiadó, 2010.
}

Este magnífico libro inaugura una colección muy prometedora, que aglutina estudios de poética y métrica en varios idiomas (inglés, francés, español e italiano) realizados por reconocidos especialistas en el ámbito de las diferentes literaturas europeas. Cada uno de los capítulos está precedido además por un abstract en inglés que resume y define el contenido del mismo.

El volumen está dedicado al estudio de las formas estróficas simples, de cuya definición y delimitación se encarga en el primero de los capítulos que funciona a modo de introducción al resto: "Formes strophiques simples: un essai de définition" uno de los coeditores del libro, Levente Seláf, que trata de aglutinar las principales aportaciones de las contribuciones recogidas. Según afirma, la invención poética principal de la Edad Media tuvo lugar gracias al nacimiento del trobar en la poesía occitana del siglo XII, a partir de la cual se sucedieron imitaciones, traducciones y contrafacta. La poesía provenzal se caracterizó por una elevada complejidad de sus esquemas poéticos, que gozaron de una riquísima variedad basada en diferentes modelos de construcción en los que la poesía mediolatina -aún muy desconocida y mal estudiada- jugó un importantísimo papel. Seláf señala el valor de los estudios agrupados en el volumen para dar una perspectiva de la presencia de la estrofa simple en todas las literaturas vernáculas y de las ventajas de realizar un estudio comparativo de este tipo. Por ello, resume las particularidades que definen los poemas de trobadours y trouvères: homogonía (o equivalencia en los esquemas de rimas masculinas y femeninas) en los primeros, considerados líricos, y heterogonía (o no coincidencia de los esquemas de rimas) en los poemas no 
líricos en lengua d'oïl. Por otra parte, hace notar las particularidades métricas de los esquemas germánicos, que obedecen a conceptos opuestos derivados de la regularización artificiosa de la misma. Además, indica que en la literatura gallego-portuguesa se distinguen las cantigas de refrán y las de meestría, unidas también a un reflejo sociológico y temático; mientras que en castellano la poesía medieval no lírica se puede resumir bajo el esquema de la cuaderna vía, como herencia de la principal estrofa no lírica francesa.

Respecto a la poesía holandesa medieval, señala que ésta se ve sometida a una triple influencia mediolatina, germánica y francesa; fenómeno muy diferente al que se analiza en este volumen sobre la poesía italiana, cuyo nacimiento de la poesía épica en estrofas tiene lugar en el siglo XIV con la creación de la ottava rima, probable origen, a su vez, de la rhyme royal británica.

El último ejemplo que recoge es el de la poesía húngara, tardía, pues sus primeros testimonios conservados se sitúan en torno a 1500, pero rica y llena de formas isométricas e isoestróficas de temática principalmente orientada hacia asuntos de tipo didáctico-moral o narrativo.

Para finalizar su introducción, explica que este volumen es el resultado de unas jornadas sobre métrica y poética comparada que tuvieron lugar en Budapest en septiembre de 2008, que reflexionaron de forma conjunta sobre asuntos como el origen latino o romance de estas formas poéticas, el uso clerical o juglaresco de las mismas, la aparición de formas comunes como el tetrástico de alejandrinos monorrimos en Inglaterra, Francia, España y Hungría con temáticas similares, la relación entre los poemas estróficos didácticos y los épicos, la definición de lírica en sí misma. El editor señala que las respuestas a estas preguntas las ofrecen los autores de forma individualizada y aplicadas a su ámbito de especialización, sin pretender dar una solución unívoca, sino crear una conciencia de la necesidad de emprender un estudio conjunto de tipo comparativo en busca de una poética medieval europea.

Pasemos ahora al resto de los capítulos. La primera contribución, realizada por el investigador italiano Francesco Stella, se ocupa de describir el proyecto del Corpus Rhythmorum Musicum (S. IV-IX), haciendo particular hincapié en la forma de 
representación métrica de la edición digital. Tras repasar los principales proyectos tecnológicos relacionados con el campo, el investigador italiano señala que existen dos modelos de edición digital: el hipertexto y la base de datos, siendo este último modelo el que ha sido utilizado en el $C R M$ que aúna ediciones de texto y música de los poemas latinos rítmicos no cuantitativos con el objetivo de llegar a reconstruir la naturaleza de estas composiciones en forma de edición abierta que permite consultar de forma simultánea las diferentes versiones y variantes de los textos en tres entregas, dos de las cuales ya han sido realizadas y la tercera se encuentra en proceso. Tras esta introducción, pasa a detallar la estructura del software, con su menú de textos, manuscritos, ediciones, búsquedas complejas, concordancias, estadísticas, una guía y una amplia bibliografía. El capítulo explica con detalle el funcionamiento de todas las posibilidades que ofrece y ofrecerá a futuro el programa y se ayuda de capturas de pantalla para ejemplificar lo expuesto. Uno de los aspectos más importantes es la representación de la métrica de los poemas, que sigue principalmente la nomenclatura adoptada por Dag Norberg y D'Angelo e incluye información sobre el esquema estrófico, de rimas y de número de sílabas de los versos.

La segunda contribución de la obra corre a cargo de una de las coeditoras del volumen, Patrizia Noel Aziz Hanna, de la Ludwitg-Maximilians-Universität München, que se ocupa del estudio del fenómeno de la anacrusis en la poesía germánica desde una perspectiva gramatical desde la cual, la anacrusis se plantea como una reliquia de la transición del orden de palabras protoindoeuropeo hacia el germano. Mientras que la frase de la izquierda en protoindoeuropeo se caracteriza por enclíticos en la segunda posición, la sintaxis germana tiene partículas proclíticas. Por ello, la autora muestra en este artículo que la anacrusis está sujeta al cambio sintáctico y es, por ello, específica y propia de cada lengua y especialmente controvertida en el caso de las germánicas, sobre las cuales se centra este trabajo, que concluye que la forma especial de la anacrusis germánica representa un buen encaje entre el sistema métrico y el gramatical, gracias a su variación.

La tercera contribución de este libro se traslada al ámbito francés y versa sobre el alejandrino en la Edad Media. Su autora, 
Jacqueline Cerquiglini-Toulet de la Université de Paris-Sorbonne realiza un estudio de este verso medieval de doce sílabas en francés, que suele estar ausente de todo poema de contenido lírico y se emplea por lo general en forma de tetrásticos para la expresión de contenidos de tipo didáctico y moralizante. Partiendo de los análisis de los tratados poéticos medievales y de la presencia de este verso en los poemas compuestos entre los siglos XII y XV, la autora concluye que este verso aparece, además, en los comienzos o finales de composiciones como marco estructural, con temática paródica en algunos casos, en epitafios y profecías e inscripciones. El estudio de la utilización no casual de un verso de este tipo para determinados contenidos hace que esta investigación se plantee la conciencia literaria de la Edad Media partiendo del análisis que los propios poetas y autores de las obras realizan sobre el propio verso, tanto durante el período medieval como en la época de los Grands Rhétoriqueurs. La importancia de este tipo de estudios resulta crucial, y no solamente referidos a la literatura francesa, puesto que este tipo de estudios en una línea muy similar, ha sido llevado a cabo recientemente en la literatura española aplicado a la cuaderna vía, designación castellana para el tetrástico monorrimo de alejandrinos ${ }^{1}$.

El capítulo siguiente, realizado también por uno de los editores del libro, el profesor húngaro Levente Seláf, de la Universidad de ELTE (Budapest), versa sobre la estrofa del Hélinand, que apareció por primera vez en un poema compuesto algo antes de 1200 por un monje cisterciense, que se hizo muy popular en poesía moral satírica e hímnica. Su forma estrófica (12 versos octosilábicos rimados aabaabbbabba) no lírica es la segunda de mayor importancia en Francia, ya que ignora el principio de la homogonía. Los propios autores se refieren a los poemas con términos no líricos, como dit, saluto, traité... La estrofa se utilizó en más de 100 poemas, entre cuyos autores destaca la figura de Adam de la Halle, así como varios poetas en los albores del siglo XIV. El poeta francés fue el primero en aplicar ciertas normas de la lírica a la estrofa, aunque lo cierto es que la estrofa

${ }^{1}$ Véase mi libro: GonzÁlez-Blanco García, Elena: La cuaderna vía española en su marco panrománico. Madrid: FUE, 2010. 
nunca fue lírica como tal, por lo que los poetas la consideraron una rareza en sí misma y casi un género literario.

Ya en el ámbito de la literatura española medieval, Fernando Baños Vallejo se ocupa del análisis de la cuaderna vía, nombre de la estrofa del tetrástico monorrimo de versos alejandrinos castellanos, y concretamente del fenómeno métrico de la dialefa, por el cual se evita sistemáticamente la realización de sinalefas entre las vocales consecutivas en este tipo de estrofa. El investigador se ocupa del estudio de este fenómeno teniendo en cuenta que en el período medieval no había fórmulas gráficas como las actuales para marcar determinados fenómenos métricos como los hiatos, y señala además que el hecho de que los textos se leyeran en voz alta suponía un factor clave para comprender la medición de los mismos.

Tras la castellana, Joost van Driel, el tercero de los coeditores del libro de la Universidad de Leiden, pasa a la poesía holandesa, en la que analiza los poemas estróficos de Jacob van Maerlant, poeta del siglo XIII que compuso 10 textos en estrofas de 13 versos con el esquema rimático aabaabaabaabb, todos ellos poemas de más de 35000 versos, de temática didáctico-moralizante, que han sido considerados obras maestras de la poesía medieval holandesa. Dicha estrofa resulta enigmática, ya que ni él mismo la emplea en más composiciones, ni ningún otro poeta europeo. El autor de este capítulo señala que la literatura épica holandesa medieval fue propensa a realizar experimentos formales y estilísticos, y este tipo de estrofa pudo ser parte de uno de estos experimentos.

El siguiente capítulo se ocupa de la literatura gallego-portuguesa, y sobre esta, Santiago Gutiérrez García, de la Universidad de Santiago de Compostela, se ocupa del estudio del paralelismo y el refrán en la configuración de los géneros. Así, señala que las formas estróficas gallego-portuguesas y en especial las cantigas de amigo utilizan con gran frecuencia el recurso del paralelismo frente a otros sistemas poéticos líricos como los trouvères, que prefieren el estribillo, fenómeno que diferencia a ambos sistemas poéticos.

Una vez realizado el recorrido a través de los diferentes países, Dominique Billy, de la Université de Toulouse-Le Mirail, 
analiza las formas poéticas simples en el tratado de las Flors del Gay Saber, un tratado occitano medieval de gramática y poética, compuesto en pareados de octosílabos y dividido en 7 partes, que presume de ser el primer tratado de este tipo en poesía romance medieval. Dicho tratado recoge ejemplos tomados de la tradición lírica del momento, pero también ilustra sus explicaciones con ejemplos originales que son los que el autor de este capítulo utiliza para su análisis de formas estróficas simples.

También francesa es la autora del siguiente capítulo, Clotilde Dauphant, de la Université François Rabelais, de Tours, que se ocupa de la heterometría "faible" (débil) o aquella que mezcla los géneros de la rima masculina y femenina, la heterometría "forte" (fuerte), que opone dos tipos de versos, por lo general uno largo y uno corto, y la isometría "pure" (pura), que usa un tipo de verso y un mismo género para todas sus estrofas (es la menos frecuente y las rimas son, por lo general, masculinas, exceptuando el caso de Christine Pizan). Estos son los principales esquemas que aparecen en las estrofas de la balada francesa medieval. La investigadora estudia el tratamiento dado por el $\mathrm{Art}$ de dictier de Deschamps (arte poética en lengua d'oïl) a este tipo de formas, así como las implicaciones métricas del género de la rima.

Siguiendo la línea de los artículos anteriores, Marco Praloran dedica un estudio a las relaciones entre las formas métricas y el discurso poético en la tradición italiana. El investigador señala que esta relación se manifiesta especialmente en la canción de Petrarca, en la que el autor juega con las diferentes estrofas como si de un tema musical de composición con variaciones se tratara, basando el argumento en una progresión oscilante propia de un monólogo interior. En el otro extremo sitúa los poemas en ottava rima como el Orlando de Boiardo y el Orlando de Ariosto, en los cuales la pausa sintáctica coincide con la métrica al final de la estrofa y marca una tensión narrativa. Mediante estos ejemplos, Praloran ilustra su hipótesis de que el discurso métrico tiene en sí un valor implícito que condiciona el contenido de lo expuesto.

R. F. Yeager, de la University of West Florida abandona el campo de la poesía romance para adentrarse en el estudio de las 
formes fixes en la literatura medieval inglesa. Dicho investigador dedica este pequeño ensayo a reflexionar si el término "lírica" puede emplearse para designar poemas que son diametralmente opuestos en literatura inglesa (se centra concretamente en poemas de Chaucer y Gower), y así, señala que la forma estrófica no es ni debe ser el único condicionante para clasificar una obra, sino que existen otros factores que comienzan en lo formal y aumentan progresivamente su complejidad hasta llegar al ámbito sociopolítico.

El siguiente capítulo está dedicado a la poesía húngara, y compuesto por uno de sus grandes especialistas, Iván Horváth, de la Universidad de ELTE, Budapest. Este trabajo tiene como objetivo demostrar, mediante el ejemplo de la poesía húngara, que en los estudios métricos el análisis comparativo basado en la cercanía geográfica de diferentes formas poéticas no resulta menos útil que su relación genética. Para ello, recorre diferentes tipos de versos húngaros y en cada uno de los casos demuestra que todos ellos pueden ser explicados mediante un origen europeo y también mediante la influencia de algunas tradiciones literarias indoeuropeas.

También sobre poesía húngara versa el epígrafe dedicado al origen del dodecasílabo húngaro, planteado como hipótesis dentro del propio título por Péter Bognár, de la Universidad de ELTE, Budapest. En dicho trabajo se explican las particularidades de la poesía húngara que no aparece manifiestamente hasta la segunda mitad del siglo XV. La mayor parte de sus poemas están compuestos en estrofas isométricas, generalmente compuestas de cuatro versos monorrimos. Una de las estrofas más frecuentes en el siglo XVI es el tetrástico de versos dodecasilábicos divididos en dos hemistiquios. En este ensayo se esboza una hipótesis para esbozar el origen de esta forma y su autor sugiere la vinculación de este tipo de estrofa con el asclepiadeo ${ }^{2}$.

${ }^{2}$ Esta hipótesis ya fue puesta en juego por D'Arco Silvio Avalle en "Le Origini Della Quartina Monorima Di Alessandrini”. Bollettino del Centro di Studi Filologici e Linguistici Siciliani, 1962, 1 [número monográfico: Saggi e Ricerche in Memoria di Ettore Li Gotti], 119-60, para explicar el origen de la estrofa castellana y francesa análoga. Sin embargo, el proceso es mucho más complejo de lo que aquí se expone, ya que entra en juego un aspecto esencial que es el paso de la métrica latina cuantitativa a la rítmica, y aún hoy se discute el papel en este 
El libro finaliza con dos riquísimos índices, uno de autores y obras y otro de términos métricos y poéticos, que remiten cuidadosamente a las páginas en las que dichos términos aparecen. Resulta por lo tanto una herramienta utilísima para emprender cualquier tipo de investigación sobre métrica medieval románica y europea, puesto que la panorámica que ofrece es actualizada, rica, muy variada y realizada por importantes especialistas en cada uno de los ámbitos. Constituye además un libro diferente a los estudios sobre métrica al uso que plantea una línea innovadora y que es, sin duda, el camino a seguir, cuyas continuaciones esperamos ansiosos.

Elena GonZÁlez-Blanco García

cambio del acento y del cómputo silábico (términos sobre los que muy a comienzos de siglo ya se debatían ilustres filólogos como Gaston Paris o Léon Gautier), que condiciona enormemente la evolución hacia uno u otro tipo de poesía. 